\title{
The Effectiveness of Communication Skills Training on Self- Efficacy and Emotional-Social Adjustment in Women with MS
}

\author{
Soodabeh Bassak Nejad', Akram Kaviani Broujeni' ${ }^{2}$, \\ Mahnaz Mehrabi Zadeh Honarmand ${ }^{3}$, Nastaran Majdi Nasab ${ }^{4}$ \\ ${ }^{1}$ Associate Professor of Psychology, Faculty of Educational Sciences, ${ }^{2}$ Master of Clinical Psychology, ${ }^{3}$ Professor of \\ Psychology, Faculty of Educational Sciences, Shahid Chamran University of Ahvaz, ${ }^{4}$ Associate Professor, Faculty \\ of Medicine, Ahvaz Jundishapur University of Medical Sciences, Ahvaz, Iran
}

\begin{abstract}
Objective: The present study aimed to evaluate the effectiveness of communication skills training on the self-efficacy and emotional-social adjustment in the women with MS in Ahvaz.

Methodology: This is an experimental study conducted with pretest-posttest design and a control group. The statistical population included the women with MS who referred to the MS Association of Ahvaz. 30 patients with a low score on self-efficacy scale were selected and they were randomly assigned into experimental/ case and control groups. The Multiple Sclerosis Self-efficacy Scaleand Bell Emotional Adjustment Inventory were used to collect the data. MANCOVA was used in order to analyze the data.
\end{abstract}

Results: The results revealed that communication skills training can enhance the self-efficacy of the MS patients and improve their adjustment level (0.001).

Conclusion: Training of communication skills can enhance the self-efficacy by improving the patients' social communication and the level of their communication with the daily external environment.

Keywords: Communication Skills Training, Self-efficacy, Adjustment, MS Patients.

\section{Introduction}

Multiple Sclerosis (MS) can be considered as one of the most prevalent demyelinating central nervous system diseases that can be chronic and progressive ${ }^{1,2}$. In this disease, the nerve sheath is gradually degraded, so that the nerve waves are not transmitted to the brain well and the symptoms of the disease emerge. In Iran, 70000 MS patients are treated by MS associations. MS disease, causes several pressures on different aspects of the patients' lives ${ }^{3}$. Psychological stress is involved in the

\section{Corresponding Author:}

Soodabeh Bassak Nejad

Associate Professor of Psychology, Faculty of

Educational Sciences, Shahid Chamran University of

Ahvaz, Ahvaz, Iran

e-mail: s.bassak@scu.ac.ir

Mobile: 01966149025 formation and development of MS, and one of the most stressful aspects of the disease is its unpredictability. When the patient is adjusting to the feeling of disability caused by previous attacks, the patient faces another attack with more restrictions ${ }^{4,5}$. The experience of many MS patients suggests a strong association between psychological stress and the disease relapse ${ }^{5}$. Severe physical disability and cognitive impairment in these patients predict job loss, reduced life standards and social contact, resulting in higher psychological stress in their families and relatives ${ }^{6}$.They often complain of fatigue following the onset of the disease, so spend several hours and days at home ${ }^{6}$.

Reduced self-efficacy is one of the most common problems in MS patients. Self-efficacy is a kind of ability of feeling competent in controlling and coping with different environmental situations. Compared to the patients with diabetes, migraine and gastrointestinal diseases, the rate of depression and fatigue caused by 
low self-efficacy is higher in MS patients ${ }^{7,8}$. Motl et al. ${ }^{7}$ suggest that self-efficacy as a mediator variable affects the quality of life of MS patients and their level of physical activity. Hence, with self-efficacy decrease, the probability of physical, cognitive and social function will increase in MS patients. Patients with MS have a negative attitude towards life and ignore their abilities in life ${ }^{9}$. Based on the Bandura's theory of self-efficacy, patients with major sources of self-efficacy, including successful and surrogate experiences, verbal persuasions, and physiological states undergo major changes in a way that this process has the greatest impact on the emotional and physiological states. These patients' personal perception of their physiological states causes them to underestimate their ability in accomplishing the tasks. High self-efficacy can predict and improve the mental health of the MS patients ${ }^{10,11}$. The results of the research carried out by Molt et al. ${ }^{12}$ suggest that there is a relationship between self-efficacy and an improvement in their walking function in patients. Emotional and social adjustment problems are another consequence of this disease ${ }^{13}$. Ghaffari et al. ${ }^{14}$ report that praying, seeking of information, social support, and hope play a key role in the adjustment of these patients. Soundy et al. ${ }^{15}$ report that three basic needs are addressed in the model of emotion, hope and adjustment in the MS patients, including independence and right to choose, coping with conditions, and control perception. Bringfelt et al. ${ }^{16}$ report that these patients avoid social situations due to communication problems. Few studies have been conducted on the effect of communication skills training on improving social communication in the MS patients. Training the communication skills to a group of MS patients, counseling and expression of the emotions in group interactions affected the fatigue, anxiety, and depression in the MS patients. Hemmatpour et al. ${ }^{17}$ reported that life skills training can enhance the self-control and self-management in these patients ${ }^{18}$.

\section{Method and Materials}

This experimental study was conducted as a pretestposttest design with a control group. All women referred to the Ahvaz MS Counseling Center from March to July 2017 were asked to complete the Washington self-efficacy scale for MS patients. Then, out of the 58 subjects who met the inclusion criteria (definitive diagnosis of the MS disease by a neurologist, score 0-5 on the disability status scale, the first type of the disease, that is, relapsing-remitting, and willingness to participate in all training sessions), 30 patients assigned into 2 groups. In order to observe the ethical considerations, the subjects were ensured that their answers would remain completely confidential. After coordinating with Ahvaz MS Association, the experimental group completed 8 sessions of communication skills training for one month and Each session lasted 120 minutes.

Two questionnaires were used to collect the data in this study, including Washington Multiple Sclerosis Self-efficacy Scale and Bell's Adjustment Inventory. The Persian version of the Washington Multiple Sclerosis Self-efficacy Scale is a 17-item self-report scale designed and validated by Emtemman et al. ${ }^{19}$ to assess the efficacy level of MS patients. It is scored on a 5-point Likert scale (1 to 5). The higher score in this scale means higher self-efficacy. This scale was retranslated by the researchers of this paper into Persian. The reliability of this scale was reported 0.90 by using Cronbach's alpha and its validity coefficient through correlating it with Efficiency Scale for Chronic Disease was reported 0.80. The Bell's Adjustment Inventoryis a self-report scale consists of 160 questions with five subscales of home adjustment, health adjustment, social adjustment, emotional adjustment, and job adjustment. Each of its questions is answered by choosing one of the three options of Yes, No, and I don't know. Cronbach's alpha reliability coefficients of this questionnaire for the subscales of home, health, social, emotional and adjustment and for the whole test were reported 0.91 , $0.81,0.88,0.91,0.85$, and 0.94 , respectively. In Iran, The validity coefficient of this questionnaire was also reported 0.78 by correlating it with Eysenck personality test.

Research Procedure: After obtaining the permission of Ahvaz MS Association, the subjects of the case group referred to Rehabilitation Conference Hall and attended the sessions. The package of training communication skills was prepared and implemented by extracting it from the UNICEF Adult Life Skills Communication Skills Book ${ }^{20}$.

\section{Communication skills sessions:}

1. Introducing group members to each other, stating the rules, goals, and necessities of learning communication skills

2. Introducing the types of verbal and nonverbal communication and the way of expressing them in different social situations

3. Explaining the barriers to communication, 
and introducing the techniques of starting and maintaining an effective communication with others.

4. The importance of self-knowledge, introducing the self-disclosure and self-expression skills

5. Introducing the listening skills and reflection of meanings and feelings and familiarity with communication patterns

6. Examining different types of self-expression and its benefits and functions, decisiveness in behavior with flexibility, developing a power of saying no, ability of demanding and assertiveness training

7. Introducing the environmental factors in the communication, the importance of eye contact,
Medico-legal Update, April-June 2020, Vol. 20, No. 2

305

transmission of the message through face movements and emotion expression

8. The way of expressing the emotions in everyday situations

9. Playing different roles in possible situations by the patients

10. Assessing the level of patients' progress and providing appropriate solutions

Data Analysis: In this study, the data were analyzed using statistical method of mean, standard deviation and multivariate analysis of covariance. The data were analyzed using SPSS software version 19 and at the $\mathrm{p} \leq 0.01$ significance level.

\section{Results}

Table 1: The mean and standard deviation of the variables of self-efficacy, emotional adjustment, and social adjustment in the case and control groups separately in pretest and posttest stages

\begin{tabular}{|l|l|c|c|c|c|}
\hline \multirow{2}{*}{ Variables } & \multirow{2}{*}{ Statistical Indices } & \multicolumn{2}{|c|}{ Case Group } & \multicolumn{2}{c|}{ Control Group } \\
\cline { 3 - 6 } & & Mean & SD & Mean & SD \\
\hline \multirow{2}{*}{ Self-Efficacy } & Pretest & 43 & 2.11 & 46.43 & 24.10 \\
\cline { 2 - 6 } & Posttest & 50 & 04.12 & 06.43 & 61.10 \\
\hline \multirow{2}{*}{$\begin{array}{l}\text { Emotional } \\
\text { Adjustment }\end{array}$} & Pretest & 20 & 67.6 & 53.19 & 34.4 \\
\cline { 2 - 6 } & Posttest & 4.16 & 89.7 & 13.19 & 77.3 \\
\hline \multirow{2}{*}{ Social Adjustment } & Pretest & 6.12 & 66.3 & 66.12 & 85.5 \\
\cline { 2 - 6 } & Posttest & 2.10 & 29.4 & 2.13 & 87.5 \\
\hline
\end{tabular}

As shown in Table 1, the mean (SD) score of the self-efficacy was 43 (11.2) in the case group and 43.46 (10.24) in the control group in the pretest stage and it was 50 (12.4) in the case group and 43.06 (10.61) in the control group in the posttest stage. The mean ( SD) score of the emotional adjustment was 20 (6.67) in the case group and 19.53 (4.34) in the control group in the pretest stage and it was 16.4 (7.89) in the case group and 19.13 (3.77) in the control group in the posttest stage. The mean (SD) score of the social adjustment was 12.6 (3.66) in the case group and 12.66 (5.85) in the control group in the pretest stage and it was 10.2 (4.29) in the case group and $12.2(5.87)$ in the control group in the posttest stage
Kolmogorov-Smirnov test results were used to determine the normality of the research variables. Its results are as follows: self-efficacy $(\mathrm{F}=0.43, \mathrm{P}=0.51)$, emotional adjustment $(\mathrm{F}=3.05, \mathrm{P}=0.09)$, and social adjustment $(\mathrm{F}=4.02, \mathrm{P}=0.06)$. The $\mathrm{F}$ ratios of the Levene's homogeneity variance test were not significant for self-efficacy and socio-emotional adjustment variables;so, the homogeneity of the variances is confirmed. In this study, the posttests of self-efficacy, emotional adjustment, and social adjustment were considered as dependent variables and their pretests were considered as covariates. 
Table 2: The results of MANCOVA on the mean scores of posttest of variables

\begin{tabular}{|l|c|c|c|c|c|c|c|}
\hline Test & Value & F & df hypothesis & df error & Significance Level & Effect Size & Statistical Power \\
\hline Pillai's Trace & 606.0 & 79.11 & 3 & 23 & $001.0 \geq \mathrm{p}$ & 606.0 & 998.0 \\
\hline Wilks' Lambda & 394.0 & 79.11 & 3 & 23 & $001.0 \geq \mathrm{p}$ & 606.0 & 998.0 \\
\hline Hotelling's Trace & 53.1 & 79.11 & 3 & 23 & $001.0 \geq \mathrm{p}$ & 606.0 & 998.0 \\
\hline Roy's Largest Root & 53.1 & 79.11 & 3 & 23 & $001.0 \geq \mathrm{p}$ & 606.0 & 998.0 \\
\hline
\end{tabular}

Table 2 illustrates that there is a significant difference between the case and control groups in terms of dependent variables at the level of $\geq 0.001$. Accordingly, it can be stated that there is a significant difference between the two groups in at least one of the dependent variables (self-efficacy, emotional adjustment and social adjustment). Three covariance analyses were performed in the MANCOVA to find this difference. Based on the calculated effect size, about $61 \%$ of the total variance of the case and control groups is explained by the independent variable effect. The statistical power of the test is also 0.99 , which means that the test rejects the null hypothesis with $99 \%$ power.

Table 3: The results of the analysis of covariance in the MANCOVA on the posttest of variables

\begin{tabular}{|c|c|c|c|c|c|c|c|}
\hline Dependent Variable & $\begin{array}{c}\text { Sum of } \\
\text { Squares }\end{array}$ & df & $\begin{array}{l}\text { Mean of } \\
\text { Squares }\end{array}$ & $\mathbf{F}$ & $\begin{array}{c}\text { Significance } \\
\text { Level }\end{array}$ & Effect Size & $\begin{array}{c}\text { Statistical } \\
\text { power }\end{array}$ \\
\hline Self-Efficacy & 95.397 & 1 & 95.397 & 78.18 & 001.0 & 43.0 & 99.0 \\
\hline Emotional Adjustment & 89.75 & 1 & 89.75 & 02.9 & 001.0 & 27.0 & 82.0 \\
\hline Social Adjustment & 63.65 & 1 & 63.65 & 11.18 & 001.0 & 42.0 & 98.0 \\
\hline
\end{tabular}

As shown in Table 3, the F-value is 18.78 for the self-efficacy variable, 9.02 for the emotional adjustment variable, and 18.11 for the social adjustment variable, all of which were significant at the level of $\mathrm{P}=0.001$. It is also seen that the highest effect size relates to the self-efficacy variable (0.43), indicating that $43 \%$ of the total variance of the case and control groups in the self-efficacy variable is explained by the independent variable effect (training of communication skills) and the least effect size relates to emotional adjustment (0.27), indicating that $37 \%$ of the total variance of the case and control groups in the emotional adjustment variable is explained by the independent variable effect (training of communication skills).

\section{Discussion}

The present study aimed to evaluate the effectiveness of training of the communication skills on self-efficacy and social-emotional adjustment in the women with MS in southwestern of Iran. The results revealed that training of the communication skills enhanced the self-efficacy and emotional adjustment, and social adjustment in the women with MS, compared to the control group. The results of this study are in line with those research conducted by Krokavcovaet al. ${ }^{21}$,Pagnin et al. ${ }^{18}$, Hemmatpoor et al. ${ }^{17}$, Motl et al. ${ }^{7}$.Psychological conditions of patients along with fatigue and hopelessness resulted in a reduction in their social communication and quality of life. Based on the results of the few research ${ }^{2,16}$, changes in the social identity of these patients cause social constraints, and training of the communication skills is effective in their presence in public settings. According to the Adjustment and Hope Model of Soundy et al. ${ }^{15}$, there are various ways to meet the need for self-management in the MS patients such as training of life and communication skills, so that they can meet their psychological and emotional needs and enhance their self-efficacy.

\section{Conclusion}

Regular trainings of communication skills can provide effective communication with others and explain the disease conditions and the physical restrictions. The way of talking and starting and terminating the conversations with others without the shame of the disease and concern of self-disclosure is one of the 
benefits of this training. In light of the trainings and performing the everyday exercises, these patients are encouraged to communicate properly with others without a concern about their physical problems. So, recommended that the communication skills packages be included in the plans of improving the patients' adjustment at the rehabilitation centers.

Ethical Consideration: Ethical issues (including plagiarism, informed consent, misconduct, data fabrication and/or submission, redundancy, etc.) have been observed by the authors.

Conflicts of Interest: The authors declare no conflicts of interest.

Acknowledgment: The authors would like to appreciate the MS Association of Ahvaz for their support. This research was adapted from a thesis approved by the Ethics committee of Shahid Chamran University of Ahvaz (EE/96.24.3.77891/scu.ac.ir).

Source of Funding: There are no sources for budget. The first author took over all the funding.

\section{References}

1. Cosio D, Jin L, Siddique J, \& Mohr D. The effect of telephone administered cognitive behavioral therapy on quality of life among pationts with Multiple Sclerosis. JBehav Med 2011;41: 227-234.

2. Lincoln N, Yuill F, \& Holmes J. Evaluation of an adjustment group for people with multiple sclerosis and low mood. Multiple Sclerosis 2011; 17(10): 1250-1257.

3. Moher DC. Stress and multipl esclerosis. Journal of Neurology 254 supp12: 1165-8

4. Patten BP, Marrie RA \& Carta MG. Depression in multiple sclerosis. Int Rev Psychiatry 2017; 29: $1-10$.

5. Hakim EA, Bakhiet M, Bryant TN, McLellan DL. The Social impact of multiple sclerosis- A study of 305 patients and their relatives. Disability and rehabilitation 2000 22(6) 288-93.

6. Schmitt, MM, Goverover Y, \& Deluca J. Selfefficacy as self-reported physical, cognitive and social functioning in multiple sclerosis. Rehabilitation Psychology 2014; 59(1): 27-34.

7. Motl RW, McAuley E, Snook EM, \& Gliottoni RC. Physical activity and quality of life in multiple sclerosis. Psychological Health Medicine 2014;
14(1): 111-124.

8. BanduraA. Toward a psychology of human agency. Perspectives on Psychological Science 2006; 1: 164-180

9. Shaker Dolagh A, Amin pur M.OptimismPessimism and self-efficacy in patients with multiple sclerosis .Health and care 2014; 17(1):4756 (In Persian).

10. RigbyS, DomenechC, Thornton E, Tedman S, \& Young C. Development and validation of a selfefficacy measure for people with multiple sclerosis. Multiple Sclerosis Journal 2013; 9(1): 73-81.

11. Riazi A, Thompson A, \& Hobart J. Self-efficacy predicts self-reported health status in multiple sclerosis. Multiple Sclerosis Journal 2004; 10(1): 61-66.

12. Molt Rw, Balto JM, Ensari I, Hubbard EA. Self efficacy and walking performance in persons with multiple sclerosis. J Neurol Phys Ther 2017, 41(2), 114-118.

13. Barker AB, Lincoln NB, Hunt N, Nair R. Social Identity in people with multiple sclerosis. Int J MS Care 2018, 20 (2), 85-91

14. Ghafari S, Fallahi- Khoshknab M, Noruzi Tabrizi K, Mohamadi E. Patientsexperience of adapting to multiple sclerosis: A qualitative study. Contemporary Nurse: A Journal for the Australian Nursing Profession 2015 50(1), 36-49.

15. Soundy A, Roskell C, Elder TM, Collet J, Dawes H. The psychological processes of adaptation and hope in patients with multiple sclerosis: A Thematic synthesis. Open Journal of Therapy and Rehabilitation 2016, 4(10), 10.4236

16. Bringfelt PA, Hartelius L, Runmaker B. Communication problems in multiple sclerosis: 9year follow-up. Int J MS Care 2006, 8, 130-140.

17. Hemmatpoor B,Gholami A,Parnian S, Seyeddoshohadaee M. The Effect of Life Skills Training on the Self-Management of Patients with Multiple Sclerosis. Journal of Medicine and Life 2018, 11(4), 387-393

18. Pagnin F,Bosma CM, Philips D, Langer E. Symptom changes in multiple sclerosis following psychological interventions: a systematic review 2014, BMC Neurology, 14, 222.

19. Amtmann D, Bamer AM, Cook KF, Askew RL, NoonanVK, \& Brockway JA. University 
of Washington self-efficacy scale: A new selfefficacy scale for people with disabilities. Archives of Physical Medicine and Rehabilitation 2012; 93(10): 1757-65.

20. Naseri H. Life Skills.Publication of Deputy of Cultural Affairs and Prevention of Welfare Organization of Iran. 2010 (In Persian)

21. .Krokavcova M, Dijk JP, Nagyova I, Rosenberger
J, Gavelova M, \& Middel B. Social support as a predictor of perceived health status in patients with multiple sclerosis. Patient Education and Counseling Journal 2008; 73(1): 159-165.

22. Dennison L, Moss-Morris R, \& Chalder T. A review of psychological correlates of adjustment in patients with multiple sclerosis. Clinical Psychology Review 2009; 29(2): 141-153. 